\title{
Janeway lesions and Osler's nodes: an indication for prompt transesophageal echocardiography
}

\author{
Beth VanderWielen, MD (D) Somnath Bose, MD
}

Received: 23 December 2016/Revised: 11 January 2017/Accepted: 24 January 2017/Published online: 1 February 2017

(C) Canadian Anesthesiologists' Society 2017

\begin{abstract}
A 28-yr-old obtunded man with a history of intravenous drug abuse presented to our emergency department. A noncontrast computed tomography scan of the brain showed a large left parietal intraparenchymal hemorrhage, prompting emergent craniotomy and evacuation of the hematoma. During placement of a neuromuscular monitor on his right foot, multiple 2-3 mm erythematous nodules were noted on his feet and pinkish erythematous papules on both palms (Figure, panels A and B). As these lesions were suggestive of Janeway lesions and Osler's nodes - known stigmata of infective endocarditis - transesophageal echocardiography initiated by the anesthesia team revealed a vegetation and perforation of the right coronary cusp of the aortic valve resulting in moderate aortic insufficiency (Figure, panel C, and videos 1 and 2 available as Electronic Supplementary Material). After cardiac surgery consultation for possible aortic valve replacement, it was decided to defer any action because of the patient's recent intracranial bleed and active drug abuse. He was thus managed medically with intravenous nafcillin for eight weeks.
\end{abstract}

Electronic supplementary material The online version of this article (doi:10.1007/s12630-017-0832-1) contains supplementary material, which is available to authorized users.

B. VanderWielen, MD $(\bowtie) \cdot S$. Bose, MD

Anesthesia, Critical Care and Pain Medicine, Beth Israel

Deaconess Medical Center, Boston, MA, USA

e-mail: bvanderw@bidmc.harvard.edu
Early diagnosis of infective endocarditis is critical to minimize morbidity and mortality. ${ }^{1,2}$ As much as a tenfold reduction in embolic events can be seen within one week of antibiotic therapy. ${ }^{2}$ Morbidity from embolic events can affect eligibility for cardiac surgery. ${ }^{1,3}$ Patients treated with both cardiac surgery and medical therapy have better outcomes than those with medical therapy alone. ${ }^{1}$

Osler's nodes and Janeway lesions are pathognomonic physical findings in patients with endocarditis. Although both originate from emboli, the pain associated with Osler's nodes is thought to be due to their manifestation in thick, dense tissue such as the fingertips or toes. In contrast, Janeway lesions generally occur on the pads of the palms and soles and are painless. Although there is some uncertainty about their pathophysiology, most sources indicate that Osler's nodes originate from sterile or septic emboli embedded in the glomus body of the dermis, whereas Janeway lesions are more commonly accepted as being dermal abscesses and thromboses of small vessels. ${ }^{4,5}$ Recognizing these key clinical signs can facilitate prompt diagnosis and subsequent treatment of infectious endocarditis. 
A

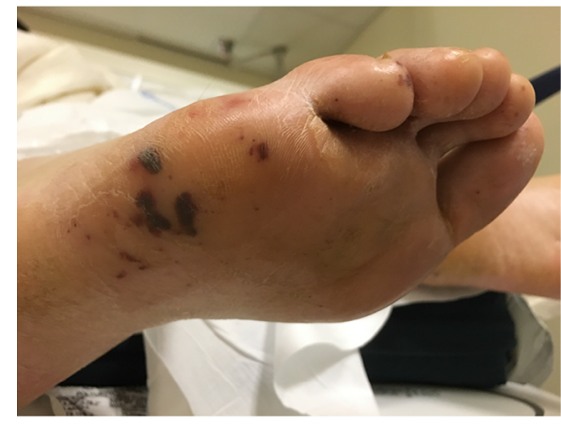

B

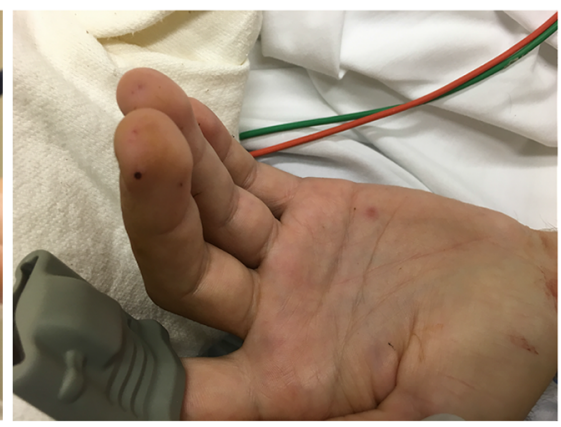

C

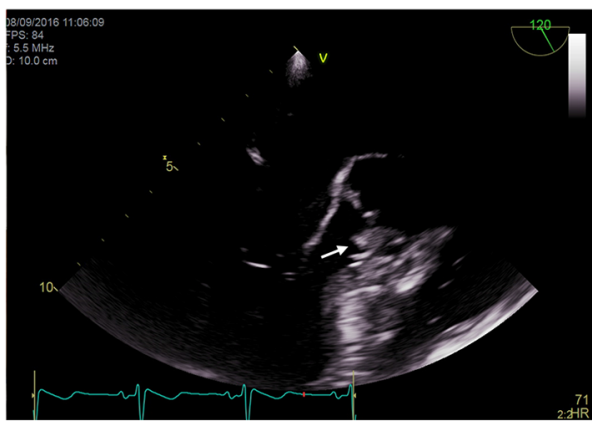

Figure Janeway lesions (A) and Osler nodes (B) discovered while placing a neuromuscular blockade monitor in a 28 -yr-old man who was undergoing emergency craniotomy to evacuate a parietal intraparenchymal hematoma. Transesophageal echocardiogrpahy in the mid-esophageal long axis view (C) revealed a large area of vegetation (arrow) on the right coronary cusp. Transesophageal

\section{Conflicts of interest None declared.}

Editorial responsibility This submission was handled by Dr. Hilary P. Grocott, Editor-in-Chief, Canadian Journal of Anesthesia.

Funding None.

\section{References}

1. Mourvillier B, Trouillet JL, Timsit JF, et al. Infective endocarditis in the intensive care unit: clinical spectrum and prognostic factors echocardiogrpahy videos, which can be viewed in the electronic supplemental file (videos 1 and 2, available as Electronic Supplementary Material), include a colour flow Doppler image that reveals perforation of the right coronary cusp in B, resulting in moderate aortic insufficiency

in 228 consecutive patients. Intensive Care Med 2004; 30: 204652.

2. Steckelberg JM, Murphy JG, Ballard D, et al. Emboli in infective endocarditis: the prognostic value of echocardiography. Ann Intern Med 1991; 114: 635-40.

3. Di Salvo G, Habib G, Pergola $V$, et al. Echocardiography predicts embolic events in infective endocarditis. J Am Coll Cardiol 2001; 37: 1069-76.

4. Cardullo AC, Silvers DN, Grossman ME. Janeway lesions and Osler's nodes: a review of histopathologic findings. J Am Acad Dermatol 1990; 22: 1088-90.

5. Marrie T. Osler's nodes and Janeway lesions. Am J Med 2008; 121: 105-6. 